\title{
Impact of Seaweed-Derived Xanthophyll Carotenoid on Obesity Management: Overview of the Last Decade
}

\author{
Oyindamola Vivian Ojulari ${ }^{1}$ Seul Gi Lee ${ }^{1}$ Ju-Ock Nam ${ }^{1,2}$ \\ ${ }^{1}$ Department of Food Science and Biotechnology, Kyungpook National University, 41566, Daegu, Republic of \\ Korea \\ 2Institute of Agricultural Science and Technology, Kyungpook National University, 41566, Daegu, Republic \\ of Korea \\ Correspondence: namjo@knu.ac.kr; Tel.: +82-53-950-7760; Fax: +82-53-950-7762
}

\begin{abstract}
Present-day lifestyle associated with high calorie-fat intake and accumulation, as well as energy imbalance, has led to the development of obesity and its comorbidities, which have emerged as some of the major health issues globally. To combat the disease, many studies have reported the anti-obesity effects of natural compounds in foods, with some advantages over chemical treatments. Carotenoids, particularly xanthophyll derived from seaweeds, have attracted the attention of researchers due to their notable biological activities, which are associated mainly with their antioxidant properties. Their involvement in oxidative stress modulation, regulation of major transcription factors and enzymes as well as their antagonistic effects on various obesity parameters have been examined in both in-vitro and in-vivo studies. The present review is a collation of published research over the last decade on the anti-oxidant properties of seaweed xanthophyll carotenoids, with a focus on fucoxanthin and astaxanthin and their mechanisms of action in obesity prevention and treatment.
\end{abstract}

Keywords: carotenoids; seaweeds; antioxidants; astaxanthin; fucoxanthin; anti-obesity; oxidative stress

\section{Introduction}

Obesity, is defined as excessive or abnormal accumulation of body fat in the adipose tissue, energy imbalance, and lipogenesis resulting from modern lifestyles characterized by high intakes of fat, sugar and calorie intake, in addition to poor exercise and physical activity [1,2]. Obesity is also associated with an increase in oxidative stress and low-grade inflammation whose intermediary molecules may include leptin, adiponectin and cytokines and leads to the development of metabolic diseases ranging from hyperglycemia, type 2 diabetes, high blood pressure, heart disease, liver disease, kidney disease, gallbladder disease, and certain types of cancer [2,3] which pose major health risks globally [4]. Specifically, obesity and type 2 diabetes are associated with an increase in oxidative stress and inflammation in adipose tissues $[2,5,6]$. Consequently, researchers have been exploring functional materials of plant origin that contain antioxidants to combat obesity and its comorbidities as alternatives to conventional approaches that have been adopted previously including surgery and anti-obesity drugs, which do not often have enduring effects and have side effects ranging from headaches, excessive thirst, insomnia, constipation, and steatorrhea [7] or may have yo-yo effects $[4,8]$. Therefore, the consideration of antioxidants as a therapeutic agent in the treatment and/or prevention of obesity and its comorbidities would be insightful.

Seaweed generally refers to plants and algae that grow in waterways such as oceans, lakes, rivers and streams. They can be classified based on their pigmentation as brown algae, red algae, 
and green algae $[9,10]$, and are natural sources of bioactive compounds such as polyphenols, lipids, and carotenoids, which exhibit antioxidant activity and other beneficial properties [11], with broad application in the food, feed, and pharmaceutical industries [12]. In some Asian countries such as Korea and Japan, seaweeds are widely consumed as functional foods for their health benefits, and are major traditional food items (e.g. Kimbap) [13, 14]. The prevalence of various metabolic syndromes in this region is reportedly lower than in western countries such as the USA and Australia [10] suggesting that dietary habits influences human health. Seaweeds contain carotenoids, which function as antioxidant, anti-viral, anti-cancer, anti-obesity, anti-inflammatory, anti-coagulant and anti-lipaemic agents[15]. Some bioactive compounds that have been isolated and identified from seaweeds include carotenoid pigments such as fucoxanthin (FXN) [16] astaxanthin (ASX), zeaxanthin, and $\beta$-carotene [17, 18].

Carotenoids are the largest group of lipid-soluble natural pigments, and they are responsible for the red, orange, and yellow colors in many fruits and vegetables $[19,20]$ Fruits and vegetables containing carotenoids have been reported to be antioxidant-rich and suitable for the formulation of functional foods to be consumed for their health benefits [21] In addition, they are associated with reduced risks of chronic diseases [22]. Dietary intake of carotenoid-containing vegetables such as seaweeds could reduce risks of development of cardiovascular disease, age- related macular degeneration, obesity, and certain cancer types [23-28] which is linked with longer life expectancy and lesser risk of metabolic diseases [29]. They have also been reported to exhibit many physiological and biological functions, including their antioxidant properties, such as quenching of singlet oxygen and radical scavenging [30]and coupled with other processes have positive impacts on human health [31]. Carotenoids are divided into carotenes and xanthophylls (e.g. FXN and ASX). Both xanthophylls and carotenes are potent antioxidants; however, xanthophylls have been reported to exhibit higher antioxidant activity, and various beneficial impacts on human physiology[32]. Xanthophylls have oxygen-containing functional group, long unsaturated aliphatic chain in their molecular structure, and are relatively abundant carotenoid in seaweeds [33]. In seaweeds, FXN and ASX are the major xanthophyll carotenoids that exhibit high antioxidant activity due to singlet oxygen quenching and free radical scavenging ability [13]. Numerous studies have investigated the antioxidant potential of the carotenoids and their metabolites with regard to their role in obesity management [26]. A recent study reported that xanthophyll intake could improve lipid metabolism and reduce abdominal fat and body Mass Index (BMI) in healthy overweight individuals [34]. Over the past decade, a new perspective on the biological function of seaweed carotenoids and their potential applications in the treatment of obesity and obesity-related diseases has emerged [31,35]. Some studies have reported the therapeutic effects of the compounds in adipose tissue biology to include adipogenesis (adipocyte differentiation), adipocyte metabolism, and oxidative stress regulation, in addition to the modulation of the expression of specific adopokines and pro-inflammatory factors [36-39]. The mechanism of action of carotenoids have been attributed to their ability to restrain adipogenesis and adipocyte hypertrophy while enhancing fat oxidation and energy dissipation in brown and white adipocytes, in turn, controlling obesity in animal models $[26,40]$.

The objective of the present review is to collate the findings of studies conducted over the past decade on the antioxidant properties of seaweed carotenoids, with a focus on xanthophylls (FXN and ASX), including findings on their relevance to obesity treatment and the mechanism of action by which they achieve the functions in-vitro (cells), in-vivo (animal models), and in clinical studies (human subjects).

\section{Antioxidant properties of selected seaweed carotenoids}

Obesity is characterized by chronic energy imbalance, excessive body weight, white adipose tissue (WAT) and lipogenesis [1, 2, 41] In addition, obesity is associated with increased oxidative 
stress and inflammation. Therefore, the functions of antioxidants in the body cannot be overemphasized. Dietary antioxidant serves as a defense system against oxidative stress and inflammation [2, 5, 42] and have received substantial attention in the potential roles in the prevention and treatment of obesity and obesity-related diseases $[3,4,6]$. One of the main biological properties of seaweed carotenoids is their antioxidant properties. When consumed in appreciable amount, edible seaweeds supply the body with potent antioxidants and enhances its ability to counteract excessive oxidative stress in the body [30]. Various seaweeds species have been demonstrated to exhibit good antioxidant effects and suppress oxidative stress in-vitro and in-vivo [43]. Studies have estimated the antioxidant properties of extract and isolates from various seaweed species using different in-vitro assays such as 2,2-Diphenyl-1-picrylhydrazyl (DPPH), ferric reducing antioxidant capacity (FRAP) or oxygen radical absorbance capacity (ORAC) and 2,2'Azino-bis(3-ethylbenzothiazoline-6-sulfonic acid (ABTS) among others. [12, 33, 44-52]. In addition, the active compounds in seaweeds such as sulphated polysaccharides, phlorotannins, and particularly carotenoids, have been suggested to be the major antioxidant compounds responsible for the beneficial health effects and a lot of research has focused on the potential applications of the bioactive compounds in obesity management $[53,54]$. As mentioned earlier, xanthophyll such as FXN and ASX exhibit greater antioxidant capacities than other seaweed carotenoids (e.g., B carotene) and, therefore, tends to have higher health benefits.

FXN, a xanthophyll carotenoid from seaweed, has been reported to exhibit high antioxidant capacity [55]. Seaweed (F. vesiculosus) extracts containing $0.0012 \%$ FXN, showed high antioxidant activity (DPPH, ABTS, and ABAP) and inactivated RAW 264.7 macrophages [16, 56]. Similarly, ASX, a red-pigmented xanthophyll, has been reported to be an antioxidant that is more effective than vitamins $C$ and E or other carotenoids [57,58]. The consumption of FXN and ASX carotenoids has been associated with reduced levels of oxidative stress-mediated inflammation in relation to obesity [36]. Over the past decade, accumulating evidence has demonstrated a link between the carotenoids and adipocyte/adipose tissue biology [35]. A recent study also revealed that the intake of xanthophylls improves lipid metabolism and reduces abdominal fat and BMI in healthy overweight individuals [34].
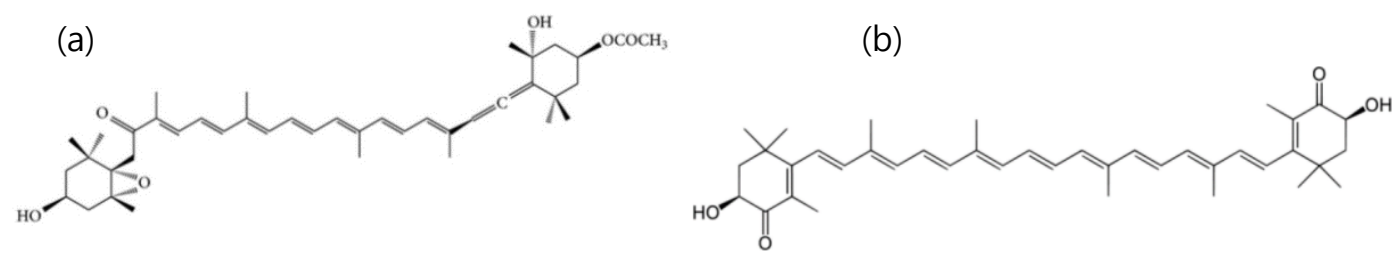

Figure 1. Chemical structure of (a) fucoxanthin and (b) astaxanthin.

\section{Fucoxanthin and Obesity}

FXN, a seaweed carotenoid has gained popularity recently due to its antioxidant properties, and is therefore considered a protective agent that could decrease the oxidative-inflammatory status associated with body weight gain and is being applied in the treatment of the various diseases triggered by obesity $[59,60]$. FXN is present in the chloroplasts of brown seaweed such as Hizikia fusiforme, Fucus serratus, Laminaria, Alaria crassifolia, japMiyatonica, Fucus vesiculosus, Sargassum horneri, and Undaria pinnatifida and have been isolated for its bioactivity [56, 61-64]. The unique characteristics of FXN lies in its structure (contains allenic bond), which accounts for its distinctive therapeutic effects [37, 64, 65]. Health-related, dietary FXN has gained substantial awareness due to its beneficial effects in human. Also, fucoxanthin was reported to possess the most effective anticarcinogenic activity among other xanthophylls, thus, fucoxanthin as well as 
other seaweed carotenoids have therapeutic potentials and could be used as nutraceuticals, functional foods ingredients and alternatives for synthetic antioxidants [66]

\subsection{Therapeutic potential of fucoxanthin in obesity.}

FXN isolated from Pinnafida binghamiae reportedly exerts anti-obesity effects in 3T3-L1 adipocytes by inhibiting the differentiation of adipocytes at both intermediate and late stages, in addition to inhibiting glucose uptake in mature adipocytes [67]. Various effects of FXN on obesity parameters have been observed with regard to body weight, visceral fat, and adipose tissues sizes, fasting blood glucose concentration, in addition to plasma insulin, lipid and cholesterol metabolism rates, among others. Reductions in bodyweight gain, WAT weight, visceral fat, hepatic total lipids, total cholesterols, and plasma and liver triglyceride concentrations are usually accompanied with increased fecal lipid excretion, which has been observed and reported in various in-vivo studies of diet-induced obesity [37, 68-71]. Based on these studies, FXN supplementation have been effective in enhancing the expression of lipid metabolizing enzymes such as carnitine palmitoyltransferase-1 (CPT1) and Cholesterol 7 $\alpha$-hydroxylase1 (CYP7A1) [39], promoting fatty acid oxidation [38, 72], and suppressing the activity of cholesterol-regulating enzymes such as 3-hydroxy-3-methylglutaryl coenzyme A reductase and acyl-coenzyme A $[37,71]$ have been used to explain the aforementioned actions. Dietary fucoxanthin supplementation in KK- $A^{y}$ mice increased serum cholesterol levels, attenuated fat accumulation and suppressed enlargement of visceral WAT during the development of obesity [59]. However, there are inconsistent reports with regard effective FXN dosages.

A low FXN concentration supplementation of $0.05 \%(\mathrm{w} / \mathrm{w})$ in mice diet was reported to lower plasma triglyceride and liver lipid concentration in HFD-fed C57BL/6N mice [37]. Surprisingly, similar effects were also observed in the same mice model, fed with a higher concentration of $0.2 \%$ fucoxanthin supplementation [37]. In another study, Sprague-Dawley rats fed with HFD and $0.2 \%$ FXN for four weeks both had significant decreases in hepatic total lipid, total cholesterol, and triglyceride concentrations compared to the HFD group [39]. Airaanthi et al., [16], reported FXN administration of about $60 \mathrm{mg} / \mathrm{kg} /$ day to cause a decrease in abdominal WAT weight of obese animal model. Meanwhile, a lower dose of $2.4 \mathrm{mg} /$ day and $3 \mathrm{mg} /$ day FXN intake reduced abdominal WAT significantly in obese female individuals with an average weight of approximately100 $\mathrm{kg}$ [38], and also reduced body weight, BMI, and abdominal fat in male and female adults [70]. The effect of FXN on anti-obesity parameters seems similar at different concentration. However, the amount or dosage of FXN required to exert certain anti-obesity effects could vary depending on study models (human or animals), due to varying sensitivity [33] or different absorption rates [64]. Therefore, further clinical studies are necessary for a more unanimous report on its effective dosage. Furthermore, as a co-administered drug, the synergetic effects of $\mathrm{FXN}$ in combination with other compounds or materials in the treatment of obesity have been investigated [38, 71]. A combination of FXN and linoleic acid decreased body weight gain and improved lipid metabolism in HFD induced obese rats [71]. Similarly, combination with pomegranate seed oil reduced body weight, liver fat, and triglyceride concentrations significantly in obese premenopausal women [38]. Also, the direct consumption of wakame seaweed (Undaria pinnatifida) which is rich in carotenoids, particularly FXN has been reported to effectively reduce postprandial glucose and insulin response in healthy adults within 30 mins of consumption with rice [73]. In fact, cooked wakame has higher FXN concentration that fresh samples [74], validating its usefulness as a functional food. With regard to toxicity, most seaweeds are edible, and thus FXN isolated from seaweeds could be considered as a safe pharmaceutical ingredient [75]. Furthermore, a clinical trial reported no abnormalities and adverse effect was exhibited by individuals who ingested FXN [70].

\subsection{Mechanisms of anti-obesity effect of fucoxanthin}


Several studies in the literature have categorized the Anti-obesity mechanism of fucoxanthin to the modulation of key transcriptional factors related with obesity. Among these, the nuclear receptor PPAR $\gamma$ and C/EBP $\alpha$ are master regulator of adipogenesis [76, 77], playing a crucial role in differentiation and function of mature adipocytes [78] The activation of this nuclear receptor in adipocytes has been reported to enhance insulin resistance associated with obesity [77, 79]. PPAR $\gamma$ is highly expressed in adipose tissues and its expression is markedly induced during adipogenesis [76, 78]. Both PPAR $\gamma$ and $\mathrm{C} / \mathrm{EBP} \alpha$, bind most induced genes linked to adipogenesis and metabolism [80], suggesting a synergistic upregulation of adipogenic gene expression by these two master regulators [81]. These nuclear receptors (PPAR $\gamma$ and C/EBP $\alpha$ ) positively regulate each other's expression [82], and cooperate to promote their respective-stimulated adipogenesis (C/EBP $\alpha$ $\leftrightarrow$ PPAR $\gamma$-stimulated adipogenesis) [77, 83].

A study by Kang et al.,[67], revealed FXN to present anti-obesogenic effects on 3T3-L1 adipocytes cells during the three differentiation (early, middle and late) stages. The promotion of adipocyte differentiation and increased protein expression of PPAR $\gamma$, CCAAT/enhancer-binding protein $\alpha(\mathrm{C} / \mathrm{EBP} \alpha)$, sterol regulatory element-binding protein 1c (SREBP1c) and adiponectin mRNA expression occurred at the early stage, while intercellular lipid accumulation was restrained by a reduction in the expressions of transcriptional factors (PPAR $\gamma, \mathrm{C} / \mathrm{EBP} \alpha$, and SREBP1c) during the intermediate and late differentiation stages of adipocyte cells. This study related the anti-obesity and anti-adipogenic effects of FXN to its structural characteristics, which promotes the down regulation of the expression of key regulatory proteins including PPARy, C/EBP $\alpha$ and SREBP1c. Further investigation confirmed that FXN treatment increased the phosphorylation of AMPK and ACC as well as LKB1 phosphorylation, and decreased the expression of SREBP1c in mature 3T3-L1 adipocytes. SREBPs (including SREBP-1a, SREBP-1c, and SREBP-2) are other key transcriptional factors similarly involved in cholesterol homeostasis, and are induced during differentiation of preadipocytes [82]. SREBP-1c regulates fatty acid and cholesterol synthesis, and has been shown to promote adipogenesis by providing lipid ligands that mediate PPAR activation [76]. FXN enhanced cholesterol synthetic pathway in the liver, by increasing transcriptional factor SREBP2 and SREBP1, and the mRNA expression levels of HMGCR, HMGCS, FDPS, and CYP51 involved in cholesterol synthesis, which decreased hepatic cholesterol content in the FXN fed mice compared with the control mice [59]. Moreover, SR-B1 and LDLR proteins (which plays an important role circulating cholesterol levels in the liver) were also observed to be downregulated by $\mathrm{FXN}$, and resulted in increased serum cholesterol levels and reduced hepatic clearance of serum cholesterol [59].

Conversely, the findings in in-vivo studies suggest that the administration of Pinnafida binghamiae extracts (containing FXN150 mg/kg/day) inhibited high-fat-diet (HFD)-induced obesity by increasing fatty acid $\beta$-oxidation and inhibiting de novo lipogenesis in adipose tissue of C57BL/6 obese mice [84]. The downregulation of stearoyl-coenzyme A desaturase-1 (SCD1), and the enhancement of insulin and leptin sensitivity have been suggested as a curative measure in HFDinduced obesity $[73,85,86]$. Leptin predominantly produced in adipose cells, regulates body and fat weights by regulating food intake and energy expenditure. A comparative in-vivo study using hyperleptinemia KK-Ay and leptin-deficiency ob/ob mice models revealed that FXN reduced body weight gain, visceral WAT mass and serum leptin levels by down-regulating hepatic SCD1 
expression through the regulation of leptin signaling in KK-Ay mice with hyperleptinemia [86]. However, the effects were not remarkable in leptin-deficient ob/ob mice, suggesting the mechanism of action of FXN to be by the down-regulation of SCD1 expression through the regulation of leptin signaling.

Another study attributed the action of FXN on insulin resistance in HFD-induced KK-Ay diabetic obese and C57BL/6J lean mice to the regulation of mRNA expression of inflammatory adipocytokines (iNOS and COX-2) in WAT of diabetic/obese KK-Ay mice [60]. Cyclooxygenases (COX) are important regulators of metabolism [87]. At the mRNA level, cyclooxygenase-1 (COX-1) is constitutively expressed in adipocytes, whereas expression of cyclooxygenase-2 (COX-2) is induced in inguinal white adipose tissue (iWAT) in response to the induction of UCP 1 [87-89]. The overexpression of COX-2 was accompanied by decreased iWAT mass and adipocyte, improved insulin-stimulated glucose disposal and reduced markers involved in hepatic steatosis in HFD C57BL/6 mice [87]. Besides, UCP1 expression in WAT is modulated by the expressions and activities of PPAR $\alpha, \operatorname{PPAR} \gamma$ [84], and COX-2 [84, 88, 89], which have been reported to be altered by fucoxanthin $[1,37,84]$.

The anti-obesity mechanism of fucoxanthin has been linked to the upregulation of uncoupling protein 1(UCP1), which is a key molecule for metabolic thermogenesis to avoid an excess of fat accumulation, and act as a physiological defense against the onset of obesity $[1,53,66,90]$. UCP1 is typically expressed in brown adipose tissue (BAT) and known as a significant component of wholebody energy expenditure [66], mediates the oxidation of fatty acids and promotes energy expenditure by thermogenesis. FXN induces (UCP1) in abdominal WAT, mediates the oxidation of fatty acids, heat production, promotes energy expenditure by thermogenesis [91]. Thus, the antiobesity effects of fucoxanthin may be related to the browning of white adipocytes through the upregulation of UCP1, which results in increased energy expenditure in the body [90].

\section{Astaxanthin and Obesity}

ASX, a red-pigmented xanthophyll carotenoid, exhibits antioxidant activity that is approximately 10 times more potent than that of any other carotenoid including $\alpha$-carotene and $\beta$ carotene [57, 92] and that is about 100 fold that of $\alpha$-tocopherol [58, 93]. Its reactive oxygen scavenging ability and anti-inflammatory properties have been studied in both in-vitro and in-vivo [94, 95] and they exhibit protective effects against metabolic diseases including cardiovascular diseases and obesity $[96,97]$. Studies have shown that the unique chemical structure (the presence of polar moieties on both ends of its polyene chain) of ASX greatly influences its antioxidant potency and ability to remove free radicals and excessive reactive oxygen species [98]. Besides possessing antioxidant activities, ASX was found to have antagonistic effects on adipocytes and agonistic effects on peritoneal macrophages, acting as a selective PPARg modulator, related to obesity [92].

ASX showed health-promoting potential such as considerable preventive and curative abilities against oxidative stress-related diseases including obesity, etc. [99]. It was suggested that ASX prevented HFD-induced obesity by lowering plasma triglyceride and total cholesterol and limiting the increase of body weight and adipose tissue. Another study showed that ASX can prevent mitochondrial damage and alleviate the oxidative stress that is associated with nonalcoholic fatty 
liver disease [100]. Thus, AXN is regarded as a promising therapeutic agent, effective and safe for obesity management. [101].

\subsection{Therapeutic potential of astaxanthin in obesity.}

Oxidative stress is a major underlying cause for metabolic disorders and is characterized by insulin resistance, which is related to obesity. Insulin is an important hormone maintaining glucose homeostasis [102]. In obese mice, fat cells were observed to be more resistant to insulin, causing the accumulation of glucose in the blood [85]. Moreover, ASX exerts beneficial effects on glucose and lipid metabolism in diet-induced animal models, by lowering insulin resistance (according to the homeostasis index of insulin resistance) and decreasing fat accumulation [103]. ASX treatment was also reported to ameliorate insulin resistance and improve insulin signaling by activating the postreceptor insulin signaling $[85,104]$, reducing oxidative stress produced by various stimuli including TNF- $\alpha$ [103], and inhibit pro-inflammatory cytokines in obese mice [85, 102]. ASX improved blood lipid profile by reducing LDL-cholesterol(LDL-C)and triglycerides(TG), increasing high-density lipoprotein cholesterol (HDL-C), and decreasing markers of lipid peroxidation [94, 105], and equally exhibited anti-obesity activity and inhibitory effects on adipogenesis in mouse models [26, 92]. In-vivo studies showed the administration of ASX to significantly reduce body weight and adipose tissue weight gain induced by a high-fat diet, and also reduced the liver weight, liver triglyceride, plasma triglyceride, and total cholesterol by stimulating an increase in fatty acid utilization [102].

Choi et al., [106] reported that ASX (5 and 20mg/day) supplementation for three weeks improved oxidative stress biomarkers by suppressing lipid peroxidation and stimulating the antioxidant defense system in human. A dose-dependent decrease in plasma malondialdehyde and isoprostane levels accompanied with increases in plasma total antioxidant capacity and superoxide dismutase levels in overweight and obese young adults were observed in the study [106]. In addition, improved antioxidant defense mechanisms and lipid metabolism following ASX supplementation has been reported in mice models [81, 97]. ASX supplementation (0.03 \%) in HFDfed apoE knockout (apoE)-/- mice reduced plasma cholesterol and triglyceride levels, however, there was no significant change in body weight when compared with the control group [97]. The observed hypocholesterolemic effect was attributed to an increase in mRNA expression of lowdensity lipoprotein receptor and fatty acid $\beta$-oxidation in the livers of ASX-fed mice. In their further studies, the authors investigated the effect of ASX on lowering plasma triacylglycerol concentrations [81]. According to their results, feeding C57BL/6J mice with 0.03\% ASX similarly exhibited significantly lower plasma triacylglycerol concentrations, with a significant increase in the fatty acid synthase and diglyceride acyltransferase 2 mRNA abundance than in the control mice. They concluded that ASX could prevent obesity-associated metabolic disturbances and inflammation by increasing hepatic expression of endogenous antioxidant genes, and rendering splenocytes less sensitive to lipopolysaccharide stimulation.

A clinical study by Yoshida et al. [96] investigated the effects of ASX on the lipid profile in humans. ASX concentrations of 12-18-mg/day reduced triglyceride concentrations significantly, which were correlated with increases in serum adiponectin hormone concentration, while 6-12$\mathrm{mg}$ /day dose increased high-density lipoprotein cholesterol significantly. However, BMI remained unaltered at all doses [96]. The increased adiponectin concentrations following ASX consumption were suggested to be due to its anti-inflammatory properties; however, it was not demonstrated in the study.

4.2. Mechanisms of anti-obesity effect of astaxanthin 
Adiponectin, an abundantly expressed adipose-specific adipokine that produces insulinsensitizing effects, and is directly involved in regulating glucose levels as well as fatty acid metabolism [107]. In obese subjects, the levels of adiponectin are usually low, which is associated with lower degrees of insulin sensitivity and glucose tolerance, and a higher adipose TNF- $\alpha$ expression [108-110]. Leptin is another important adipokine abundantly expressed in adipose tissue and is involved in the balancing of energy homeostasis [107]. Leptin helps to control food intake, energy expenditure, and, hence, body weight [108].

In this point of view, the anti-obesity mechanism of ASX might be mediated by improving adipokine levels (i.e. $\downarrow$ leptin level and $\uparrow$ adiponectin level). In fact, ASX-mediated adiponectin elevation has been observed in human trials [96]. Since adiponectin is regulated by the peroxisome proliferator-activated receptor- $\gamma(\operatorname{PPAR} \gamma)$ pathway and is involved in close-inhibition relationships with inflammatory cytokines [96], the dysregulation of the nuclear receptor peroxisome proliferator-activated receptor $\delta / \beta(\mathrm{PPAR} \delta / \beta)$ could be associated with obesity, because of its key role in lipid metabolism [111]. Arunkumar et al., [85] attributed the improvement in insulin resistance, reduced lipid levels and adipose tissue weight observed in obese mice to PPAR $\gamma$ agonist and modulation effects of ASX supplementation. Furthermore, ASX was reported to bind PPAR $\gamma$ selectively in a dose-dependent manner, and inhibited rosiglitazone (a PPAR $\gamma$ ligand) induced adipogenesis in 3T3-L1 cells by antagonizing PPAR $\gamma$ transcriptional activity, upon direct binding $[40,92]$. Clearly, the integrated activation of PPARS/ $\beta$ (connecting the muscle and adipose tissue) by ASX could have led to the induction of non-shivering thermogenesis, in turn reducing fat accumulation in adipocytes and controlling body fat reduction [111].

In obesity-induced insulin resistance, inflammatory cytokines and free fatty acids (FFAs) released from adipose tissue are involved in insulin sensitivity [112], and are reportedly caused by abnormal insulin signaling in obese models [113]. High glucose and fatty acid levels associated with obesity leads to increased ROS production which causes insulin resistance in metabolic tissues [114]. The beneficial effect of ASX on ROS induced- insulin resistance in obese mouse models has been linked to the modulation of signaling pathways primarily mitogen-activated protein kinases (MAPK) and JNK (c-Jun N-terminal kinases) pathways [85, 113]. Since collated evidence confirms the role of cytokines such as TNF- $\alpha$ in the promotion of insulin resistance by generation of ROS or the activation of JNK in inflammatory pathway signaling, the inhibition of JNK could be an important target for the treatment of inflammation-induced insulin resistance or abnormal glucose tolerance in obesity $[113,114]$. As a potent antioxidant, ASX reportedly improved insulin resistance, through the JNK-IRS-1-Akt axis by suppressing insulin-induced JNK phosphorylation as well as IRS-1 serine phosphorylation in the liver of HFD mouse [104, 114]. Also, ASX significantly decreased ROS produced by oxidants including TNF- $\alpha$ and enhanced Akt phosphorylation related to the increase in GLUT4 translocation or glucose uptake [103].

The expression of nuclear factor erythroid 2-related factor 2 (NRF-2), a responsive antioxidant gene plays a critical role in cellular defense against oxidative stress by inducing the transcription of antioxidant genes, and decreasing the concentrations of oxidative stress marker such as glutathione disulfide (GSSG) in the liver of mice [81]. ASX has been able to enhance the antioxidant defense mechanisms as well as prevented non-alcoholic fatty liver disease (NAFLD) by improving lipid metabolism in HFD fed C57BL/6J and apoE 2/2 mice [81, 97]. The mechanism was further explained to be due to the induction of NRF-2 which caused a significant 2-fold increase in the mRNA expression of NRF-2 as well as an increased expression of its target endogenous antioxidant genes, including superoxide dismutase 1, glutamate-cysteine ligase regulatory subunit and glutathione peroxidase 1, in the liver of ASX-fed mice [81,98]. Some recent studies have substantiated that 
NRF-2 inducers improve insulin resistance in obesity models and increase glucose uptake by decreasing oxidative stress in the hypothalamus $[115,116]$.

Additionally, Yang et al., [81] reported the TAG lowering effects of ASX as observed in ASX supplemented mice and was attributed to the expression of genes involved in lipogenesis and fatty acid b-oxidation. The increase in the mRNA expression of acyl-CoA oxidase 1 (ACOX-1), increases in the hepatic expression of 3-hydroxy-3-methylglutaryl-CoA reductase (HMGR) and LDL receptor and the rate-limiting enzyme in the peroxisomal fatty acid b-oxidation were observed in ASX-fed mice, however, no difference was observed in that of SREBP-2 [81, 97].

Overall, ASX has been proven by various studies as beneficial natural antioxidant that improves insulin resistance, lipid metabolism and ameliorates oxidative stress-induced obesity. Moreover, the ingestion of ASX is considered safe [32, 93, 94, 117].

\section{Conclusion}

The prevalence of obesity is of global concern, with accumulated evidence tending towards oxidative stress-induced maladies, making the supplementation of natural antioxidant a feasible intervention. This review presented the relationships between antioxidants, oxidative stress, inflammation, and obesity, with clear illustrating that seaweed carotenoids are antioxidant-packed bioactive compounds with potent oxidative defense mechanisms and anti-obesity properties. Xanthophyll carotenoids (FXN and ASX) as described in the reviewed studies positively modulated the expressions of various transcriptional factors, cytokines, and enzymes associated with obesity, substantiating their therapeutic potentials for obesity management. The molecular mechanisms of action on various obesity parameters have been highlighted in this review. Moreover, these xanthophyll carotenoids have proven to positively mediate the abnormalities caused by excess ROS and depletion of antioxidant system in obese subjects. Thus, a detailed understanding of their mechanisms could evolve new ideas in the treatment of obesity and peripheral metabolic diseases. Based on the safety and molecular mechanisms highlighted, FXN and ASX showed good pharmacological effects on obesity and could be potential materials for functional foods and drugs for human health benefits. 


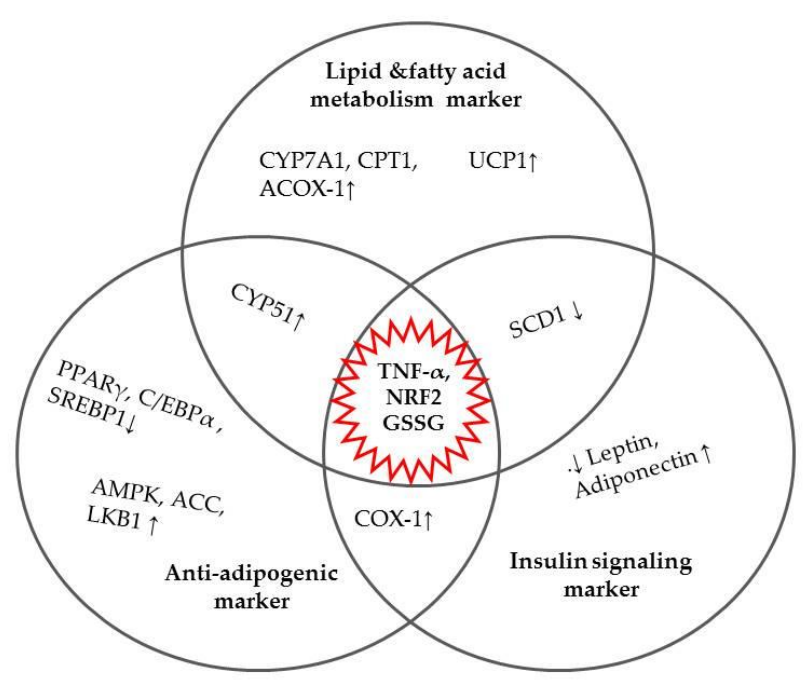

Figure. 2 Transcription factors, mRNA expressions and cytokines involved in the antiobesity mechanism of FXN, and ASX Xanthophyll Carotenoids 
Table 1. Reported studies on the effect of selected xanthophylls and their anti-obesity effects.

\begin{tabular}{|c|c|c|c|c|c|}
\hline s/n & Subject/Model & Effective dose & Seaweed Specie & Observed effect & References \\
\hline 1 & Male Sprague Dawley Rat & $\begin{array}{l}0.083 \text { and } 0.167 \mathrm{mg} / \mathrm{kg} / \mathrm{bw} \mathrm{FXN} \\
\text { supplementation in HFD }\end{array}$ & not mentioned & $\begin{array}{l}\text { Reduces plasmatic and hepatic triglyceride concentrations and positively influenced } \\
\text { cholesterol-regulating enzymes such as 3-hydroxy-3-methylglutarylcoenzyme A reductase and } \\
\text { acyl-coenzyme A }\end{array}$ & {$[71]$} \\
\hline 2 & Obese KK-Ay mice & $0.2 \% \mathrm{FXN}$ diet & Undaria pinnatifida & $\begin{array}{l}\text { Increased High-Density Lipoprotein (HDL)-cholesterol and non-HDL-cholesterol levels in KK- } \\
\text { Ay mice, reduced cholesterol uptake in the liver, via down-regulation of Low-Density } \\
\text { Lipoprotein (LDL)-receptor and (Scavenger Receptor class B member 1) SR-B1 }\end{array}$ & [59] \\
\hline 3 & $\begin{array}{l}\text { KK-Ay mice and B6.V- } \\
\text { Lepob/J (ob/ob) mice }\end{array}$ & $\begin{array}{c}0.1 \text { or } 0.2 \% \text { FXN supplemented } \\
\text { diet } \\
\end{array}$ & Undaria pinnatifida & Suppressed body weight, visceral WAT mass, and lowered serum leptin levels & [86] \\
\hline 4 & $\begin{array}{l}\text { KK-Ay mice/ lean } \\
\text { C57BL/6J mice }\end{array}$ & & & FXN regulated adipocytokine mRNA expression in WAT of diabetic/obese KK-Ay mice & [53] \\
\hline 5 & Mice & $150 \mathrm{mg} / \mathrm{kg} /$ day & Petalonia binghamiae & $\begin{array}{c}\text { PBE (or FXN) exert improving effects on HFD-induced obesity by promoting } \beta \text {-oxidation and } \\
\text { reducing lipogenesis. }\end{array}$ & [84] \\
\hline 6 & $\begin{array}{l}\text { C57BL/6J and KK-Ay } \\
\text { mice }\end{array}$ & $0.2 \%$ fucoxanthin FXN & Undaria pinnatifida & $\begin{array}{c}\text { FXN regulated mRNA expression of inflammatory adipocytokines, attenuated both body } \\
\text { weight gain and WAT weight in diabetic/obese KK-Ay mice, but did not affect these } \\
\text { parameters in lean C57BL/6J mice }\end{array}$ & [60] \\
\hline 7 & $\begin{array}{l}\text { obese female volunteers } \\
\text { with } 100 \mathrm{~kg} \text { average } \\
\text { weight }\end{array}$ & $2.4 \mathrm{mg} / \mathrm{kg} /$ day & Undaria pinnatifida & Increased energy expenditure in the body and resulted in significant weight loss after 16 weeks & [38] \\
\hline 9 & KK-Ay mice & $\begin{array}{l}60 \mathrm{mg} \text { FXN intake/kg body } \\
\text { weight/day }\end{array}$ & $\begin{array}{c}\text { Undaria pinnatifida (Wakame), } \\
\text { Sargassum horneri (Akamoku), and } \\
\text { Cystoseira hakodatensis (Uganomoku) }\end{array}$ & $\begin{array}{c}\text { Significant decrease in liver lipid hydroperoxide levels and abdominal WAT weight of obese } \\
\text { model }\end{array}$ & [16] \\
\hline 11 & C57BL/6N mice & $\begin{array}{l}0.05 \% \text { and } 0.2 \% \text { FXN in diet, } \\
\mathrm{w} / \mathrm{w}\end{array}$ & Undaria pinnatifida & $\begin{array}{c}\text { FXN supplementation improves plasma and hepatic lipid metabolism and blood glucose } \\
\text { concentration }\end{array}$ & [37] \\
\hline 12 & C57BL/6J mice & $0.02 \%$ dose & Undaria pinnatifida & Ethanol extract on diet-induced-insulin resistance in C57BL/6J mice & [69] \\
\hline 13 & C57BL/6J mice & $\begin{array}{c}0.05 \text { or } 0.2 \% \text { FXN } \\
\text { supplemented diet }\end{array}$ & Undaria pinnatifida & $\begin{array}{l}\text { Regulated the plasma and hepatic lipids metabolism; increased fecal lipid excretion. Fecal } \\
\text { weight, liver and triglycerides and cholesterol were not significantly different between } 0.05 \\
\text { and } 0.2 \% \text { FX fed mice }\end{array}$ & [72] \\
\hline 14 & $\begin{array}{l}30 \text { male } 4 \text {-week-old } \\
\text { C57BL/6 mice }\end{array}$ & $\begin{array}{l}\text { Oral; } 150 \mathrm{mg} / \mathrm{kg} / \text { day for } \\
\text { 70days }\end{array}$ & Petalonia binghamiae & $\begin{array}{c}\text { Extract (PBE) administration e reduced body weight gain, adipose tissue weight, adipose cell } \\
\text { size, serum triglyceride level, and reduced lipid accumulation in the liver in HFD-induced } \\
\text { obese mice. }\end{array}$ & [84] \\
\hline 15 & 3T3-L1 adipocyte & $10 \mathrm{uM}$ treatment & Petalonia binghamiae & $\begin{array}{l}\text { FXN activated the AMPK signaling pathway; increased the phosphorylation of LKB1, AMPK, } \\
\text { and ACC and inhibited the expression of PPAR } \gamma, \text { C/EBP } \alpha \text {, and SREBP1c in mature 3T3-L1 } \\
\text { adipocytes. }\end{array}$ & {$[67,84]$} \\
\hline
\end{tabular}




\begin{tabular}{|c|c|c|c|c|c|}
\hline 16 & Sprague-Dawley rats & $0.2 \% \mathrm{FXN}$ powder in feed & Undaria pinnatifida & $\begin{array}{l}\text { The hepatic total lipids, total cholesterols, and triglycerides were significantly decreased while } \\
\text { the fecal excretions of total lipids, cholesterol, and triglycerides were significantly increased in } \\
\text { HFD+Fx group }\end{array}$ & [39] \\
\hline 17 & Sprague-Dawley rats & $\begin{array}{l}5 \% \text { seaweeds powder } \\
\text { supplemented in HFD }\end{array}$ & $\begin{array}{c}\text { Eucheuma cottonii; aulerpa lentillifera, } \\
\text { and Sargassum polycystum }\end{array}$ & $\begin{array}{l}\text { All seaweeds significantly reduced body weight gain, and plasma lipid peroxidation of HCF } \\
\text { diet rats. However S. polycystum showed the best anti-obesity properties }\end{array}$ & [43] \\
\hline 18 & $\begin{array}{l}\text { KK-Ay mice and B6.V- } \\
\text { Lepob/J (ob/ob) mice }\end{array}$ & $\begin{array}{c}0.1 \text { or } 0.2 \% \text { FXN supplemented } \\
\text { diet }\end{array}$ & Undaria pinnatifida & Suppressed body weight, visceral WAT mass, and lowered serum leptin levels & [86] \\
\hline 19 & C57BL/6N mice & $\begin{array}{l}0.05 \text { or } 0.2 \% \mathrm{FXN} \\
\text { supplemented diet }\end{array}$ & Undaria pinnatifida & $\begin{array}{l}\text { Regulated the plasma and hepatic lipids metabolism; increased fecal lipid excretion. Fecal } \\
\text { weight, liver and triglycerides and cholesterol were not significantly different between } 0.05 \\
\text { and } 0.2 \% \text { FX fed mice }\end{array}$ & [72] \\
\hline 20 & Human & 6,12, and $18 \mathrm{mg} /$ day of ASX & Haematococcus pluvialis & $\begin{array}{c}12 \text { and } 18 \mathrm{mg} / \text { day improved the serum lipid profile in humans (decrease in TG levels } \\
\text { observed), } 6 \text { and } 12 \mathrm{mg} / \text { day increased HDL-cholesterol, however BMI values remained } \\
\text { unchanged }\end{array}$ & [96] \\
\hline 21 & Male C57BL/6J mice & $\begin{array}{l}\text { HF diet supplemented 0.003, } \\
0.01 \text { and } 0.03 \% \text { of ASTX (by } \\
\text { weight) }\end{array}$ & Hematococcus pluvialis & $\begin{array}{c}0.03 \% \text { ASX fed group showed significantly lowered triacylglycerol concentrations increased the } \\
\text { hepatic expression of endogenous antioxidant genes }\end{array}$ & [81] \\
\hline 22 & $\begin{array}{l}\text { male apoE knockout } \\
\text { (apoE)-/- mic }\end{array}$ & $0.03 \%$ ASX & Haematococcus pluvialis & $\begin{array}{l}\text { ASX-rich H. pluvialis extract improves cholesterol and lipid metabolism as well as antioxidant } \\
\text { defense mechanisms }\end{array}$ & [97] \\
\hline 23 & male Swiss albino mice & $6 \mathrm{mg} \mathrm{kg}^{-1}$ per day for 60 days & Haematococcus pluvialis & $\begin{array}{l}\text { ASX treatment reduced lipid accumulation and oxidative stress and adipose tissue weight. } \\
\text { Also improved insulin sensitivity }\end{array}$ & [85] \\
\hline 24 & $\begin{array}{c}\text { Human; verweight and } \\
\text { obese young adults }\end{array}$ & $\begin{array}{l}5 \mathrm{mg} \text { and } 20 \mathrm{mg} \text { soft ASX } \\
\text { capsule }\end{array}$ & not mentioned & $\begin{array}{l}\text { Improved lipid metabolism and prevented oxidative stress by stimulating the activity of the } \\
\text { antioxidant defense system }\end{array}$ & [106] \\
\hline
\end{tabular}


Author Contributions: Conceptualization, O.V.O, S.G.L, and J.-O.N.; Literature collection and Writing-original draft, O.V.O; Review \& Editing, O.V.O, S.G.L, and J.-O.N; Supervision, J.-O.N.

Conflicts of Interest: The authors declare no conflict of interest

\section{Abbreviations}

ABTS 2,2'-Azino-bis (3-ethylbenzothiazoline-6-sulfonic acid

DPPH 2,2-Diphenyl-1-picrylhydrazyl

ABAP 2,2'-azobis(2-amidopropane)

ACC Acetyl-CoA carboxylase

AMPK AMP-activated protein kinase

ASX Astaxanthin

BMI Body mass index

TNF- $\alpha \quad$ Tumor necrosis factor $\alpha$

$\mathrm{C} / \mathrm{EBP} \alpha \quad$ CCAAT Enhancer Binding Protein Alpha

COX-2 Cyclooxygenase-2,

FRAP Ferric reducing antioxidant capacity

FXN Fucoxanthin

iNOS Inducible nitric oxide synthase

mRNA Messenger RNA

ORAC Oxygen radical absorbance capacity

PPAR $\gamma \quad$ Peroxisome Proliferator-activated Receptor $\gamma$

SCD1 Stearoyl-coenzyme A desaturase-1

SREBP-1c Sterol regulatory element-binding protein

WAT White adipose tissue

\section{References}

1. Gammone, M. A.; D'Orazio, N., Anti-obesity activity of the marine carotenoid fucoxanthin. Marine drugs 2015, 13, (4), 2196-2214.

2. Abdali, D.; Samson, S. E.; Grover, A. K., How effective are antioxidant supplements in obesity and diabetes? Medical Principles and Practice 2015, 24, (3), 201-215.

3. Laura Segal, J.; Martin, A., The State of Obesity: Better Policies for a Healthier America 2016. Robert Wood Johnson Foundation 2016.

4. Ojulari, O. V.; Lee, S. G.; Nam, J.-O., Beneficial effects of natural bioactive compounds from Hibiscus sabdariffa L. on obesity. Molecules 2019, 24, (1), 210.

5. Gregor, M. F.; Hotamisligil, G. S., Inflammatory mechanisms in obesity. Annual review of immunology 2011, 29, 415-445.

6. Marseglia, L.; Manti, S.; D'Angelo, G.; Nicotera, A.; Parisi, E.; Di Rosa, G.; Gitto, E.; Arrigo, T., Oxidative stress in obesity: a critical component in human diseases. International journal of molecular sciences 2015, 16, (1), 378-400.

7. Sung, Y.-Y.; Yoon, T.; Yang, W.-k.; Kim, S. J.; Kim, H. K., Article Inhibitory Effects of Elsholtzia ciliata Extract on Fat Accumulation in High-fat Diet-induced Obese Mice. Journal of the Korean Society for Applied Biological Chemistry 2011, 54, (3), 388-394. 
8. Annamalai, S.; Mohanam, L.; Alwin, D.; Prabhu, V., Effect of combination therapy of melatonin and orlistat on high fat diet induced changes in lipid profiles and liver function parameters in serum of rats. Obesity Medicine 2016, 2, 41-45.

9. Lordan, S.; Ross, R. P.; Stanton, C., Marine bioactives as functional food ingredients: potential to reduce the incidence of chronic diseases. Marine drugs 2011, 9, (6), 10561100.

10. Kumar, S. A.; Brown, L., Seaweeds as potential therapeutic interventions for the metabolic syndrome. Reviews in Endocrine and Metabolic Disorders 2013, 14, (3), 299308.

11. Ngo, D.-H.; Wijesekara, I.; Vo, T.-S.; Van Ta, Q.; Kim, S.-K., Marine food-derived functional ingredients as potential antioxidants in the food industry: An overview. Food Research International 2011, 44, (2), 523-529.

12. Rajauria, G.; Foley, B.; Abu-Ghannam, N., Identification and characterization of phenolic antioxidant compounds from brown Irish seaweed Himanthalia elongata using LC-DADESI-MS/MS. Innovative food science \& emerging technologies 2016, 37, 261-268.

13. Li, Y.-X.; Kim, S.-K., Utilization of seaweed derived ingredients as potential antioxidants and functional ingredients in the food industry: An overview. Food Science and Biotechnology 2011, 20, (6), 1461-1466.

14. Brownlee, I.; Fairclough, A.; Hall, A.; Paxman, J., The potential health benefits of seaweed and seaweed extract. 2012.

15. Boominathan, M.; Mahesh, A., Seaweed carotenoids for cancer therapeutics. In Handbook of Anticancer Drugs from Marine Origin, Springer: 2015; pp 185-203.

16. Airanthi, M. W.-A.; Sasaki, N.; Iwasaki, S.; Baba, N.; Abe, M.; Hosokawa, M.; Miyashita, K., Effect of brown seaweed lipids on fatty acid composition and lipid hydroperoxide levels of mouse liver. Journal of agricultural and food chemistry 2011, 59, (8), 4156-4163.

17. Plaza, M.; Santoyo, S.; Jaime, L.; Reina, G. G.-B.; Herrero, M.; Señoráns, F. J.; Ibáñez, E., Screening for bioactive compounds from algae. Journal of pharmaceutical and biomedical analysis 2010, 51, (2), 450-455.

18. de Quirós, A. R.-B.; Frecha-Ferreiro, S.; Vidal-Perez, A.; López-Hernández, J., Antioxidant compounds in edible brown seaweeds. European Food Research and Technology 2010, 231, (3), 495-498.

19. Namitha, K.; Negi, P., Chemistry and biotechnology of carotenoids. Critical reviews in food science and nutrition 2010, 50, (8), 728-760.

20. Haskell, M. J., Provitamin A carotenoids as a dietary source of vitamin A. In Carotenoids and human health, Springer: 2013; pp 249-260.

21. Olawuyi, I. F.; Lee, W. Y., Quality and antioxidant properties of functional rice muffins enriched with shiitake mushroom and carrot pomace. International Journal of Food Science \& Technology 2019, 54, (7), 2321-2328. 
22. Jiménez-Escrig, A.; Gómez-Ordóñez, E.; Rupérez, P., Seaweed as a source of novel nutraceuticals: sulfated polysaccharides and peptides. In Advances in food and nutrition research, Elsevier: 2011; Vol. 64, pp 325-337.

23. Fernández-García, E.; Carvajal-Lérida, I.; Jarén-Galán, M.; Garrido-Fernández, J.; PérezGálvez, A.; Hornero-Méndez, D., Carotenoids bioavailability from foods: From plant pigments to efficient biological activities. Food Research International 2012, 46, (2), 438450.

24. Sharoni, Y.; Linnewiel-Hermoni, K.; Khanin, M.; Salman, H.; Veprik, A.; Danilenko, M.; Levy, J., Carotenoids and apocarotenoids in cellular signaling related to cancer: a review. Molecular nutrition \& food research 2012, 56, (2), 259-269.

25. Meyers, K. J.; Mares, J. A.; Igo, R. P.; Truitt, B.; Liu, Z.; Millen, A. E.; Klein, M.; Johnson, E. J.; Engelman, C. D.; Karki, C. K., Genetic evidence for role of carotenoids in age-related macular degeneration in the Carotenoids in Age-Related Eye Disease Study (CAREDS). Investigative ophthalmology \& visual science 2014, 55, (1), 587-599.

26. Bonet, M. L.; Canas, J. A.; Ribot, J.; Palou, A., Carotenoids and their conversion products in the control of adipocyte function, adiposity and obesity. Archives of biochemistry and biophysics 2015, 572, 112-125.

27. Leermakers, E. T.; Darweesh, S. K.; Baena, C. P.; Moreira, E. M.; Melo van Lent, D.; Tielemans, M. J.; Muka, T.; Vitezova, A.; Chowdhury, R.; Bramer, W. M., The effects of lutein on cardiometabolic health across the life course: a systematic review and metaanalysis, 2. The American journal of clinical nutrition 2016, 103, (2), 481-494.

28. Milani, A.; Basirnejad, M.; Shahbazi, S.; Bolhassani, A., Carotenoids: biochemistry, pharmacology and treatment. British journal of pharmacology 2017, 174, (11), 12901324.

29. Seca, A. M.; Pinto, D. C., Overview on the antihypertensive and anti-obesity effects of secondary metabolites from seaweeds. Marine drugs 2018, 16, (7), 237.

30. Stahl, W.; Sies, H., Photoprotection by dietary carotenoids: concept, mechanisms, evidence and future development. Molecular nutrition \& food research 2012, 56, (2), 287-295.

31. Rodriguez-Concepcion, M.; Avalos, J.; Bonet, M. L.; Boronat, A.; Gomez-Gomez, L.; Hornero-Mendez, D.; Limon, M. C.; Meléndez-Martínez, A. J.; Olmedilla-Alonso, B.; Palou, A., A global perspective on carotenoids: Metabolism, biotechnology, and benefits for nutrition and health. Progress in lipid research 2018, 70, 62-93.

32. Terasaki, M.; Mutoh, M.; Fujii, G.; Takahashi, M.; Ishigamori, R.; Masuda, S., Potential ability of xanthophylls to prevent obesity-associated cancer. World Journal of Pharmacology 2014, 3, (4), 140-152.

33. Mikami, K.; Hosokawa, M., Biosynthetic pathway and health benefits of fucoxanthin, an algae-specific xanthophyll in brown seaweeds. International journal of molecular 
sciences 2013, 14, (7), 13763-13781.

34. Kakutani, R.; Hokari, S.; Nishino, A.; Ichihara, T.; Sugimoto, K.; Takaha, T.; Kuriki, T.; Maoka, T., Effect of Oral Paprika Xanthophyll Intake on Abdominal Fat in Healthy Overweight Humans: A Randomized, Double-blind, Placebo-controlled Study. Journal of oleo science 2018, ess18076.

35. Mounien, L.; Tourniaire, F.; Landrier, J.-F., Anti-obesity effect of carotenoids: direct impact on adipose tissue and adipose tissue-driven indirect effects. Nutrients 2019, 11, (7), 1562.

36. Cho, S. O.; Kim, M.-H.; Kim, H., $\beta$-Carotene Inhibits Activation of NF-kB, Activator Protein1, and STAT3 and Regulates Abnormal Expression of Some Adipokines in 3T3-L1 Adipocytes. Journal of cancer prevention 2018, 23, (1), 37.

37. Woo, M.-N.; Jeon, S.-M.; Kim, H.-J.; Lee, M.-K.; Shin, S.-K.; Shin, Y. C.; Park, Y.-B.; Choi, M.S., Fucoxanthin supplementation improves plasma and hepatic lipid metabolism and blood glucose concentration in high-fat fed $\mathrm{C} 57 \mathrm{BL} / 6 \mathrm{~N}$ mice. Chemico-Biological Interactions 2010, 186, (3), 316-322.

38. Abidov, M.; Ramazanov, Z.; Seifulla, R.; Grachev, S., The effects of Xanthigen ${ }^{\mathrm{TM}}$ in the weight management of obese premenopausal women with non-alcoholic fatty liver disease and normal liver fat. Diabetes, obesity and metabolism 2010, 12, (1), 72-81.

39. Ha, A. W.; Kim, W. K., The effect of fucoxanthin rich power on the lipid metabolism in rats with a high fat diet. Nutrition research and practice 2013, 7, (4), 287-293.

40. Bonet, M. L.; Canas, J. A.; Ribot, J.; Palou, A., Carotenoids in adipose tissue biology and obesity. In Carotenoids in Nature, Springer: 2016; pp 377-414.

41. Lee, S. G.; Lee, Y. J.; Jang, M.-H.; Kwon, T. R.; Nam, J.-O., Panax ginseng leaf extracts exert anti-obesity effects in high-fat diet-induced obese rats. Nutrients 2017, 9, (9), 999.

42. Aldini, G.; Yeum, K.-J.; Niki, E.; Russell, R. M., Biomarkers for antioxidant defense and oxidative damage: principles and practical applications. John Wiley \& Sons: 2011.

43. Matanjun, P.; Mohamed, S.; Muhammad, K.; Mustapha, N. M., Comparison of cardiovascular protective effects of tropical seaweeds, Kappaphycus alvarezii, Caulerpa lentillifera, and Sargassum polycystum, on high-cholesterol/high-fat diet in rats. Journal of medicinal food 2010, 13, (4), 792-800.

44. Sullivan, O.; AM, O. C.; MN, Q., B., Hanniffy, D., Troy, DJ, Kerry, JP, OBrien NM 2011. vitro and cellular antioxidant activities of seaweed extracts prepared from five brown seaweeds harvested in spring from the west coast of Ireland. Food Chem 126, 10641070.

45. Martins, C. D. L.; Ramlov, F.; Carneiro, N. P. N.; Gestinari, L. M.; dos Santos, B. F.; Bento, L. M.; Lhullier, C.; Gouvea, L.; Bastos, E.; Horta, P. A., Antioxidant properties and total phenolic contents of some tropical seaweeds of the Brazilian coast. Journal of applied phycology 2013, 25, (4), 1179-1187. 
46. Devi, G. K.; Manivannan, K.; Thirumaran, G.; Rajathi, F. A. A.; Anantharaman, P., In vitro antioxidant activities of selected seaweeds from Southeast coast of India. Asian Pacific journal of tropical medicine 2011, 4, (3), 205-211.

47. Kumar, M.; Gupta, V.; Kumari, P.; Reddy, C.; Jha, B., Assessment of nutrient composition and antioxidant potential of Caulerpaceae seaweeds. Journal of Food Composition and Analysis 2011, 24, (2), 270-278.

48. Cox, S.; Abu-Ghannam, N.; Gupta, S., An assessment of the antioxidant and antimicrobial activity of six species of edible Irish seaweeds. International Food Research Journal 2010, $17,205-220$.

49. Rajauria, G.; Jaiswal, A. K.; Abu-Ghannam, N.; Gupta, S., Effect of hydrothermal processing on colour, antioxidant and free radical scavenging capacities of edible Irish brown seaweeds. International journal of food science \& technology 2010, 45, (12), 2485-2493.

50. Boonchum, W.; Peerapornpisal, Y.; Kanjanapothi, D.; Pekkoh, J.; Pumas, C.; Jamjai, U.; Amornlerdpison, D.; Noiraksar, T.; Vacharapiyasophon, P., Antioxidant activity of some seaweed from the Gulf of Thailand. International Journal of Agriculture and Biology 2011, 13, (1).

51. Rajauria, G.; Jaiswal, A. K.; ABU-GANNAM, N.; Gupta, S., Antimicrobial, antioxidant and free radical-scavenging capacity of brown seaweed Himanthalia elongata from western coast of Ireland. Journal of Food Biochemistry 2013, 37, (3), 322-335.

52. Ganesan, K.; Kumar, K. S.; Rao, P. S., Comparative assessment of antioxidant activity in three edible species of green seaweed, Enteromorpha from Okha, Northwest coast of India. Innovative food science \& emerging technologies 2011, 12, (1), 73-78.

53. Miyashita, K.; Maeda, H.; Okada, T.; Abe, M.; Hosokawa, M., Anti-obesity and antidiabetic effects of allenic carotenoid, fucoxanthin. Agro Food Ind Hi Tech 2010, 21, (6), 24-27

54. Mohamed, S.; Hashim, S. N.; Rahman, H. A., Seaweeds: a sustainable functional food for complementary and alternative therapy. Trends in Food Science \& Technology 2012, 23, (2), 83-96.

55. Fung, A.; Hamid, N.; Lu, J., Fucoxanthin content and antioxidant properties of Undaria pinnatifida. Food chemistry 2013, 136, (2), 1055-1062.

56. Peng, J.; Yuan, J.-P.; Wu, C.-F.; Wang, J.-H., Fucoxanthin, a marine carotenoid present in brown seaweeds and diatoms: metabolism and bioactivities relevant to human health. Marine drugs 2011, 9, (10), 1806-1828.

57. Mata, T. M.; Martins, A. A.; Caetano, N. S., Microalgae for biodiesel production and other applications: a review. Renewable and sustainable energy reviews 2010, 14, (1), 217-232.

58. Campoio, T.; Oliveira, F.; Otton, R., Oxidative stress in human lymphocytes treated with fatty acid mixture: role of carotenoid astaxanthin. Toxicology in vitro 2011, 25, (7), 14481456. 
59. Beppu, F.; Hosokawa, M.; Niwano, Y.; Miyashita, K., Effects of dietary fucoxanthin on cholesterol metabolism in diabetic/obese KK-A y mice. Lipids in health and disease $\mathbf{2 0 1 2 ,}$ 11, (1), 112.

60. Hosokawa, M.; Miyashita, T.; Nishikawa, S.; Emi, S.; Tsukui, T.; Beppu, F.; Okada, T.; Miyashita, K., Fucoxanthin regulates adipocytokine mRNA expression in white adipose tissue of diabetic/obese KK-Ay mice. Archives of Biochemistry and Biophysics 2010, 504, (1), 17-25.

61. Takaichi, S., Carotenoids in algae: distributions, biosyntheses and functions. Marine drugs 2011, 9, (6), 1101-1118.

62. Kim, S. M.; Jung, Y.-J.; Kwon, O.-N.; Cha, K. H.; Um, B.-H.; Chung, D.; Pan, C.-H., A potential commercial source of fucoxanthin extracted from the microalga Phaeodactylum tricornutum. Applied biochemistry and biotechnology 2012, 166, (7), 1843-1855.

63. Kumar, S. R.; Hosokawa, M.; Miyashita, K., Fucoxanthin: A marine carotenoid exerting anti-cancer effects by affecting multiple mechanisms. Marine drugs 2013, 11, (12), 51305147.

64. Miyashita, K., Anti-obesity therapy by food component: unique activity of marine carotenoid, fucoxanthin. Obes Control Ther 2014, 1, (1), 4.

65. Kim, K.-N.; Ahn, G.; Heo, S.-J; Kang, S.-M.; Kang, M.-C.; Yang, H.-M.; Kim, D.; Roh, S. W.; Kim, S.-K.; Jeon, B.-T., Inhibition of tumor growth in vitro and in vivo by fucoxanthin against melanoma B16F10 cells. Environmental Toxicology and Pharmacology 2013, 35, (1), 39-46.

66. Pangestuti, R.; Siahaan, E. A., Seaweed-Derived Carotenoids. In Bioactive Seaweeds for Food Applications, Elsevier: 2018; pp 95-107.

67. Kang, S.-I.; Ko, H.-C.; Shin, H.-S.; Kim, H.-M.; Hong, Y.-S.; Lee, N.-H.; Kim, S.-J., Fucoxanthin exerts differing effects on $3 \mathrm{~T} 3-\mathrm{L} 1$ cells according to differentiation stage and inhibits glucose uptake in mature adipocytes. Biochemical and biophysical research communications 2011, 409, (4), 769-774.

68. Perez-Torres, I.; Ruiz-Ramirez, A.; Banos, G.; El-Hafidi, M., Hibiscus sabdariffa Linnaeus (Malvaceae), curcumin and resveratrol as alternative medicinal agents against metabolic syndrome. Cardiovascular \& hematological agents in medicinal chemistry 2013, 11, (1), 25-37.

69. Park, H.; Lee, M.; Park, Y.; Shin, Y.; Choi, M., Beneficial effects of Undaria pinnatifida ethanol extract on diet-induced-insulin resistance in C57BL/6J mice. Food and chemical toxicology 2011, 49, (4), 727-733.

70. Hitoe, S.; Shimoda, H., Seaweed fucoxanthin supplementation improves obesity parameters in mild obese Japanese subjects. Functional Foods in Health and Disease 2017, 7, (4), 246-262.

71. Hu, X.; Li, Y.; Li, C.; Fu, Y.; Cai, F.; Chen, Q.; Li, D., Combination of fucoxanthin and 
conjugated linoleic acid attenuates body weight gain and improves lipid metabolism in high-fat diet-induced obese rats. Archives of biochemistry and biophysics 2012, 519, (1), 59-65.

72. Jeon, S. M.; Kim, H. J.; Woo, M. N.; Lee, M. K.; Shin, Y. C.; Park, Y. B.; Choi, M. S., Fucoxanthin-rich seaweed extract suppresses body weight gain and improves lipid metabolism in high-fat-fed C57BL/6J mice. Biotechnology journa/ 2010, 5, (9), 961-969.

73. Yoshinaga, K.; Mitamura, R., Effects of Undaria pinnatifida (Wakame) on Postprandial Glycemia and Insulin Levels in Humans: a Randomized Crossover Trial. Plant Foods for Human Nutrition 2019, 74, (4), 461-467.

74. Amorim, K.; Lage-Yusty, M.-A.; López-Hernández, J., Changes in bioactive compounds content and antioxidant activity of seaweed after cooking processing. CyTA-Journal of Food 2012, 10, (4), 321-324.

75. Zhang, H.; Tang, Y.; Zhang, Y.; Zhang, S.; Qu, J.; Wang, X.; Kong, R.; Han, C.; Liu, Z., Fucoxanthin: A promising medicinal and nutritional ingredient. Evidence-based complementary and alternative medicine 2015, 2015.

76. Lee, J.-E.; Schmidt, H.; Lai, B.; Ge, K., Transcriptional and epigenomic regulation of adipogenesis. Molecular and cellular biology 2019, 39, (11), e00601-18.

77. Wang, Y.-X., PPARs: diverse regulators in energy metabolism and metabolic diseases. Cell research 2010, 20, (2), 124-137.

78. Eeckhoute, J.; Oger, F.; Staels, B.; Lefebvre, P., Coordinated Regulation of PPAR. PPAR research 2012, 2012.

79. Schupp, M.; Lazar, M. A., Endogenous ligands for nuclear receptors: digging deeper. Journal of Biological Chemistry 2010, 285, (52), 40409-40415.

80. Siersbæk, R.; Nielsen, R.; Mandrup, S., PPARY in adipocyte differentiation and metabolism-Novel insights from genome-wide studies. FEBS letters 2010, 584, (15), 3242-3249.

81. Yang, Y.; Pham, T. X.; Wegner, C. J.; Kim, B.; Ku, C. S.; Park, Y.-K.; Lee, J.-Y., Astaxanthin lowers plasma TAG concentrations and increases hepatic antioxidant gene expression in diet-induced obesity mice. British journal of nutrition 2014, 112, (11), 1797-1804.

82. Lee, J.-E.; Ge, K., Transcriptional and epigenetic regulation of PPARY expression during adipogenesis. Cell \& bioscience 2014, 4, (1), 29.

83. Ghaben, A. L.; Scherer, P. E., Adipogenesis and metabolic health. Nature Reviews Molecular Cell Biology 2019, 20, (4), 242-258.

84. Kang, S.-I.; Shin, H.-S.; Kim, H.-M.; Yoon, S.-A.; Kang, S.-W.; Kim, J.-H.; Ko, H.-C.; Kim, S.-J., Petalonia binghamiae extract and its constituent fucoxanthin ameliorate high-fat dietinduced obesity by activating AMP-activated protein kinase. Journal of agricultural and food chemistry 2012, 60, (13), 3389-3395.

85. Arunkumar, E.; Bhuvaneswari, S.; Anuradha, C. V., An intervention study in obese mice 
with astaxanthin, a marine carotenoid-effects on insulin signaling and pro-inflammatory cytokines. Food \& function 2012, 3, (2), 120-126.

86. Beppu, F.; Hosokawa, M.; Yim, M. J.; Shinoda, T.; Miyashita, K., Down-regulation of hepatic stearoyl-CoA desaturase-1 expression by Fucoxanthin via leptin signaling in diabetic/obese KK-Ay mice. Lipids 2013, 48, (5), 449-455.

87. Danneskiold-Samsøe, N. B.; Sonne, S. B.; Larsen, J. M.; Hansen, A. N.; Fjære, E.; Isidor, M. S.; Petersen, S.; Henningsen, J.; Severi, I.; Sartini, L., Overexpression of cyclooxygenase-2 in adipocytes reduces fat accumulation in inguinal white adipose tissue and hepatic steatosis in high-fat fed mice. Scientific reports 2019, 9, (1), 1-13.

88. Madsen, L.; Pedersen, L. M.; Lillefosse, H. H.; Fjære, E.; Bronstad, I.; Hao, Q.; Petersen, R. K.; Hallenborg, P.; Ma, T.; De Matteis, R., UCP1 induction during recruitment of brown adipocytes in white adipose tissue is dependent on cyclooxygenase activity. PloS one 2010, 5, (6).

89. Vegiopoulos, A.; Müller-Decker, K.; Strzoda, D.; Schmitt, I.; Chichelnitskiy, E.; Ostertag, A.; Diaz, M. B.; Rozman, J.; De Angelis, M. H.; Nüsing, R. M., Cyclooxygenase-2 controls energy homeostasis in mice by de novo recruitment of brown adipocytes. Science 2010, 328, (5982), 1158-1161.

90. Wu, J.; Boström, P.; Sparks, L. M.; Ye, L.; Choi, J. H.; Giang, A.-H.; Khandekar, M.; Virtanen, K. A.; Nuutila, P.; Schaart, G., Beige adipocytes are a distinct type of thermogenic fat cell in mouse and human. Cel/ 2012, 150, (2), 366-376.

91. Petrovic, N.; Walden, T. B.; Shabalina, I. G.; Timmons, J. A.; Cannon, B.; Nedergaard, J., Chronic peroxisome proliferator-activated receptor $\gamma$ (PPAR $\gamma$ ) activation of epididymally derived white adipocyte cultures reveals a population of thermogenically competent, UCP1-containing adipocytes molecularly distinct from classic brown adipocytes. Journal of Biological Chemistry 2010, 285, (10), 7153-7164.

92. Inoue, M.; Tanabe, H.; Matsumoto, A.; Takagi, M.; Umegaki, K.; Amagaya, S.; Takahashi, J., Astaxanthin functions differently as a selective peroxisome proliferator-activated receptor $\gamma$ modulator in adipocytes and macrophages. Biochemical pharmacology 2012, 84, (5), 692-700.

93. Ambati, R. R.; Phang, S.-M.; Ravi, S.; Aswathanarayana, R. G., Astaxanthin: sources, extraction, stability, biological activities and its commercial applications-a review. Marine drugs 2014, 12, (1), 128-152.

94. Fassett, R. G.; Coombes, J. S., Astaxanthin in cardiovascular health and disease. Molecules 2012, 17, (2), 2030-2048.

95. Yamashita, E., Astaxanthin as a medical food. Functional Foods in Health and Disease 2013, 3, (7), 254-258.

96. Yoshida, H.; Yanai, H.; Ito, K.; Tomono, Y.; Koikeda, T.; Tsukahara, H.; Tada, N., Administration of natural astaxanthin increases serum $\mathrm{HDL}$-cholesterol and adiponectin 
in subjects with mild hyperlipidemia. Atherosclerosis 2010, 209, (2), 520-523.

97. Yang, Y.; Seo, J. M.; Nguyen, A.; Pham, T. X.; Park, H. J.; Park, Y.; Kim, B.; Bruno, R. S.; Lee, J., Astaxanthin-rich extract from the green alga Haematococcus pluvialis lowers plasma lipid concentrations and enhances antioxidant defense in apolipoprotein $E$ knockout mice. The Journal of nutrition 2011, 141, (9), 1611-1617.

98. Yang, Y.; Kim, B.; Lee, J. Y., Astaxanthin structure, metabolism, and health benefits. J. Hum. Nutr. Food Sci 2013, 1, (1003), 1-1003.

99. Yuan, J. P.; Peng, J.; Yin, K.; Wang, J. H., Potential health-promoting effects of astaxanthin: a high-value carotenoid mostly from microalgae. Molecular nutrition \& food research 2011, 55, (1), 150-165.

100. McCarty, M. F., Full-spectrum antioxidant therapy featuring astaxanthin coupled with lipoprivic strategies and salsalate for management of non-alcoholic fatty liver disease. Medical hypotheses 2011, 77, (4), 550-556.

101. Lee, J.; Li, Y.; Li, C.; Li, D., Natural products and body weight control. North American journal of medical sciences 2011, 3, (1), 13.

102. Zhang, J.; Sun, Z.; Sun, P.; Chen, T.; Chen, F., Microalgal carotenoids: beneficial effects and potential in human health. Food \& function 2014, 5, (3), 413-425.

103. Ishiki, M.; Nishida, Y.; Ishibashi, H.; Wada, T.; Fujisaka, S.; Takikawa, A.; Urakaze, M.; Sasaoka, T.; Usui, I.; Tobe, K., Impact of divergent effects of astaxanthin on insulin signaling in L6 cells. Endocrinology 2013, 154, (8), 2600-2612.

104. Bhuvaneswari, S.; Anuradha, C. V., Astaxanthin prevents loss of insulin signaling and improves glucose metabolism in liver of insulin resistant mice. Canadian journal of physiology and pharmacology 2012, 90, (11), 1544-1552.

105. Maria, A. G.; Graziano, R.; Nicolantonio, D. O., Carotenoids: potential allies of cardiovascular health? Food \& nutrition research 2015, 59, (1), 26762.

106. Choi, H. D.; Kim, J. H.; Chang, M. J.; Kyu-Youn, Y.; Shin, W. G., Effects of astaxanthin on oxidative stress in overweight and obese adults. Phytotherapy Research 2011, 25, (12), 1813-1818.

107. Jung, U. J.; Choi, M.-S., Obesity and its metabolic complications: the role of adipokines and the relationship between obesity, inflammation, insulin resistance, dyslipidemia and nonalcoholic fatty liver disease. International journal of molecular sciences 2014, 15, (4), 6184-6223.

108. Stern, J. H.; Rutkowski, J. M.; Scherer, P. E., Adiponectin, leptin, and fatty acids in the maintenance of metabolic homeostasis through adipose tissue crosstalk. Cell metabolism 2016, 23, (5), 770-784.

109. Furukawa, S.; Fujita, T.; Shimabukuro, M.; Iwaki, M.; Yamada, Y.; Nakajima, Y.; Nakayama, O.; Makishima, M.; Matsuda, M.; Shimomura, I., Increased oxidative stress in obesity and its impact on metabolic syndrome. The Journal of clinical investigation 2017, 114, (12), 
1752-1761.

110. Ouchi, N.; Parker, J. L.; Lugus, J. J.; Walsh, K., Adipokines in inflammation and metabolic disease. Nature reviews immunology 2011, 11, (2), 85.

111. Jia, Y.; Kim, J. Y.; Jun, H. J.; Kim, S. J.; Lee, J. H.; Hoang, M. H.; Hwang, K. Y.; Um, S. J.; Chang, H. I.; Lee, S. J., The natural carotenoid astaxanthin, a PPAR- $\alpha$ agonist and PPAR- $\gamma$ antagonist, reduces hepatic lipid accumulation by rewiring the transcriptome in lipidloaded hepatocytes. Molecular nutrition \& food research 2012, 56, (6), 878-888.

112. Makki, K.; Froguel, P.; Wolowczuk, I., Adipose tissue in obesity-related inflammation and insulin resistance: cells, cytokines, and chemokines. ISRN inflammation 2013, 2013.

113. Rains, J. L.; Jain, S. K., Oxidative stress, insulin signaling, and diabetes. Free Radical Biology and Medicine 2011, 50, (5), 567-575.

114. Berdichevsky, A.; Guarente, L.; Bose, A., Acute oxidative stress can reverse insulin resistance by inactivation of cytoplasmic JNK. Journal of Biological Chemistry 2010, 285, (28), 21581-21589.

115. Yagishita, Y.; Uruno, A.; Fukutomi, T.; Saito, R.; Saigusa, D.; Pi, J.; Fukamizu, A.; Sugiyama, F.; Takahashi, S.; Yamamoto, M., Nrf2 improves leptin and insulin resistance provoked by hypothalamic oxidative stress. Cell reports 2017, 18, (8), 2030-2044.

116. Francisqueti-Ferron, F. V.; Ferron, A. J. T.; Garcia, J. L.; Silva, C. C. V. d. A.; Costa, M. R.; Gregolin, C. S.; Moreto, F.; Ferreira, A. L. A.; Minatel, I. O.; Correa, C. R., Basic concepts on the role of nuclear factor erythroid-derived 2-like 2 (Nrf2) in age-related diseases. International journal of molecular sciences 2019, 20, (13), 3208.

117. Park, J. S.; Chyun, J. H.; Kim, Y. K.; Line, L. L.; Chew, B. P., Astaxanthin decreased oxidative stress and inflammation and enhanced immune response in humans. Nutrition \& metabolism 2010, 7, (1), 18. 